\title{
L-histidine enhances learning in stressed zebrafish
}

\author{
L.P.V. Cofiel and R. Mattioli \\ Laboratório de Neurociências, Departamento de Fisioterapia, Universidade Federal de São Carlos, \\ São Carlos, SP, Brasil \\ Correspondence to: R. Mattioli, Departamento de Fisioterapia, Universidade Federal de São Carlos, \\ Rodovia Washington Luiz, km 235, 13565-905 São Carlos, SP, Brasil \\ Fax: +55-16-3361-2081. E-mail: mattioli@ufscar.br
}

\begin{abstract}
The aim of the present study was to determine the effect of the histaminergic precursor L-histidine and the $\mathrm{H}_{3}$ receptor antagonist thioperamide on the learning process of zebrafish submitted or not to confinement stress. On each of the 5 consecutive days of experiment (D1, D2, D3, D4, D5), animals had to associate an interruption of the aquarium air supply with food offering. Nonstressed zebrafish received an intraperitoneal injection of $100 \mathrm{mg} / \mathrm{kg} \mathrm{L-histidine,} 10 \mathrm{mg} / \mathrm{kg}$ thioperamide or saline after training. Stressed animals received drug treatment and then were submitted to confinement stress for $1 \mathrm{~h}$ before the learning procedure. Time to approach the feeder was measured (in seconds) and was considered to be indicative of learning. A decrease in time to approach the feeder was observed in the saline-treated group (D1 = 141.92 \pm 13.57 ; $D 3=55 \pm 13.54$ ), indicating learning. A delay in learning of stressed animals treated with saline was observed $(D 1=217.5 \pm 25.66)$. L-histidine facilitated learning in stressed (D1 = 118.68 $\pm 13.9 ; \mathrm{D} 2=45.88 \pm 8.2)$ and non-stressed (D1 = 151.11 $\pm 19.20 ; \mathrm{D} 5=62 \pm 14.68)$ animals. Thioperamide inhibited learning in non-stressed $(D 1=110.38 \pm 9.49$; $D 4=58.79 \pm 16.83)$ and stressed animals $(D 1=167.3 \pm 26.39 ; D 5=172.15 \pm$ 27.35). L-histidine prevented the increase in blood glucose after one session of confinement (L-histidine $=65.88 \pm 4.50$; control $=53 \pm 3.50 \mathrm{mg} / \mathrm{dL}$ ). These results suggest that the histaminergic system enhances learning and modulates stress responses in zebrafish.
\end{abstract}

Key words: Danio rerio; Conditioning; Feed trial; Thioperamide; $\mathrm{H}_{3}$ receptor; Blood glucose

Presented at the IV Miguel R. Covian Symposium, Ribeirão Preto, SP, Brazil, May 23-25, 2008.

Research supported by FAPESP (\#04/10659-0) and CNPq (\#300312/2007-5).

Received July 28, 2008. Accepted January 19, 2009

\section{Introduction}

The histaminergic system is involved in different physiological and behavior processes such as wakefulness, sleep-wake cycle, appetite control, learning, memory, and emotion (for reviews, see Refs. 1 and 2).

Histaminergic neurons are present in the caudal hypothalamus, sending out axons that innervate most parts of the central nervous system. All vertebrates studied contain a well-conserved system of histaminergic neurons (3-6). In zebrafish, all the histaminergic neurons are concentrated in the vicinity of the posterior recess. The morphology, intracellular storage, distribution, and projection patterns in the brain seem to have been highly conserved throughout evolution, or at least among teleosts and mammals (7).

The zebrafish has received attention because it is useful in genetic studies, for its rapid life cycle, easy handling and genetic manipulation (8). Recently, these animals have been used in behavioral studies, but few investigations have used this species for the study of the role of the histaminergic system in learning (2).

Several studies have shown that the manipulation of the histaminergic central system results in modification of animal behavior in different learning paradigms, although with contradictory results. Both facilitatory and inhibitory effects of histaminergic drugs have been reported in mam- 
mals and fish $(2,9)$.

The histaminergic system is also involved in stressrelated processes. The highest histaminergic fiber density is found in the hypothalamus, where histamine is involved in the regulation of autonomic and neuroendocrine functions (10). The stress system coordinates the adaptive responses of the organism to stressors of any kind. Activation of the stress system leads to behavioral and peripheral changes that improve the ability of the organism to adjust homeostasis and increase its chances of survival (11). One of the first physiological alterations is the secretion of glucocorticoids and catecholamines, hormones that are responsible for energy mobilization to be used for the reestablishment of homeostasis (12).

The stress response of teleost fish is similar to that of land vertebrates, including function, with elevated consumption and transfer of oxygen, mobilization of energy substrates, decreased energy use for growth and reproduction, and suppressive effects on immune functions (13). Fish respond to stressors with the release of glucocorticoids and catecholamines, which raise glucose production (14). Although the increase in glucose is only a secondary response to stress that follows the release of glucocorticoids and catecholamines, it has been used as an indicator of stress $(14,15)$.

There is evidence that a relationship between learning impairment and stress exists. Both learned helplessness and chronic mild stress significantly decreased the cognitive performance of stressed mice in the water maze task (16). The same investigators observed that chronic mild stress induces the activation of the neuroendocrine and neuroimmune systems, which potentially promote cell damage and decreased neurogenesis and impair cognitive function in mice (17). A deleterious effect of stress on fish cognition was also observed, since isolation stress inhibited active avoidance learning in goldfish (18). The capacity of fish to evoke a stress response to a neutral stimulus was also demonstrated $(19,20)$. Moreover, it was observed that chronically elevated blood cortisol levels in a line of rainbow trout with high responsiveness to a stressor (21)

Table 1. Description of the experimental groups.

\begin{tabular}{lclcc}
\hline $\begin{array}{l}\text { Experimental } \\
\text { condition }\end{array}$ & $\mathrm{N}$ & \multicolumn{1}{c}{ Drug } & Dose & $\begin{array}{c}\text { Fish body } \\
\text { weight }(\mathrm{g})\end{array}$ \\
\hline Non-stressed & 26 & Saline & - & $0.45 \pm 0.03$ \\
Non-stressed & 25 & L-histidine & $100 \mathrm{mg} / \mathrm{kg}$ & $0.49 \pm 0.03$ \\
Non-stressed & 24 & Thioperamide & $10 \mathrm{mg} / \mathrm{kg}$ & $0.44 \pm 0.03$ \\
Stressed & 18 & Saline & - & $0.54 \pm 0.03$ \\
Stressed & 18 & L-histidine & $100 \mathrm{mg} / \mathrm{kg}$ & $0.48 \pm 0.05$ \\
Stressed & 22 & Thioperamide & $10 \mathrm{mg} / \mathrm{kg}$ & $0.43 \pm 0.03$ \\
\hline
\end{tabular}

and chronic administration of exogenous cortisol to fish (22) interfered with cognitive performance.

Since the histaminergic system is involved in stress and in the learning process, the aim of the present study was to investigate the effect of the histaminergic precursor L-histidine and the $\mathrm{H}_{3}$ receptor antagonist thioperamide on the learning process of zebrafish submitted or not to confinement stress.

The experiments carried out in this study complied with the norms of the Brazilian Neuroscience and Behavior Society (SBNeC), based on the US National Institutes of Health Guidelines for the Care and Use of Laboratory Animals.

\section{Material and Methods}

\section{Animals}

A total of 133 naive zebrafish of unknown sex were used. An acclimatization interval of at least 1 week was allowed from the time of purchase of the fish to the beginning of the experiment. The animals were placed in $30-\mathrm{L}$ aquaria (30 animals per aquarium) at $18-22^{\circ} \mathrm{C}$ with constant filtering and aeration, under a natural light cycle and fed flake food (Wardly Corporation, USA) five times a week.

\section{Experimental design}

The animals were weighed and placed individually in the aquaria two days before the beginning of the experiments and did not receive food during this period. The experiment was carried out on five consecutive days (D1, D2, D3, D4, and D5), one fish at a time. The procedure was the same on all 5 training days. The air supply was turned off and after $30 \mathrm{~s}$ food was offered inside the feeder. The time (in seconds) the fish took to enter the feeding area from the moment the air supply was turned off was recorded and considered to be indicative of learning. Animals that did not eat on the first training day were excluded.

The experiment involved stressing and non-stressing conditions. In the first one, animals received drug treatment 5 min after each training procedure and in the second, $5 \mathrm{~min}$ after receiving the drug injections (on the 5 training days), the animals were confined for $1 \mathrm{~h}$ by a plastic transparent barrier in an area corresponding to $8 \%$ of the total aquarium area. One hour after confinement, the animals were submitted to the training procedure as described above. The animals were divided into the experimental groups described in Table 1. Mean ( \pm SEM) fish weights were not different for both treatments (ANOVA).

Experimental aquarium

The aquaria used in this experiment were $25 \mathrm{~cm}$ long, 
$11.5 \mathrm{~cm}$ wide and $15 \mathrm{~cm}$ high and the water was constantly aired. A transparent plastic barrier was fixed $6 \mathrm{~cm}$ from one side of the aquarium, limiting a feeding area. A plastic transparent cylinder was placed inside this area, where food was offered during the experiments.

\section{Drugs}

The drugs used in both experiments were the histamine precursor L-histidine dissolved in saline to a concentration of $50 \mathrm{mg} / \mathrm{mL}$ and the $\mathrm{H}_{3}$ receptor antagonist, thioperamide maleat salt (Sigma, USA) dissolved in saline at a concentration of $5 \mathrm{mg} / \mathrm{mL}$. The drugs were administered intraperitoneally (ip) in a volume of $2 \mathrm{~mL} / \mathrm{kg}$ body weight using a $10-\mu \mathrm{L}$ syringe (Hamilton, model $7105 \mathrm{KH}$, USA). These doses were chosen on the basis of the literature $(23,24)$.

Saline was used as control. Both drugs and vehicle were stored in coded Eppendorf tubes under refrigeration. The code was unknown to the experimenter at the time of the tests.

\section{Blood glucose analysis}

Blood glucose analysis was carried out in animals selected from the second experiment after training on the first and the fifth day of confinement. This analysis was also carried out in one group of non-stressed and noninjected animals used as control.

The animals were decapitated and blood glucose was determined using Accu-Check Advantage II blood glucose strips and the Accu-Check Advantage monitor (Roche Diagnostics, Germany).

\section{Statistical analysis}

Statistical analysis was carried out using the GB-STAT School Pack software, version 1997. Data are reported as means \pm SEM. Since the data obtained in the two experiments were not homogeneously distributed, they were analyzed by the non-parametric Friedman test followed by the Dunn multiple comparison test when appropriate. To determine if confinement affected the learning of the animals, the latencies to enter the feeding area by the animals treated with saline in experiments 1 and 2 were compared by the Mann-Whitney U-test, with the level of significance set at $P<0.05$. Since the data for the glucose experiment were homogeneous, they were analyzed by parametric two-way-ANOVA followed by the Student-Newman-Keuls test.

\section{Results}

The data for the non-stressed animals are shown in
Figure 1. The animals treated with saline after training presented a significant decrease of the latency to enter the feeding area after day $3\left(P<0.0001\right.$, d.f. $=4, \chi^{2}=35,752$, Friedman test; $\mathrm{P}<0.05$, Dunn test). Animals treated with thioperamide presented a significant decrease of the latency to enter the feeding area after day $4(P<0.0001$, d.f. $=4, \chi^{2}=30,025$, Friedman test; $P<0.05$, Dunn test), while the group treated with L-histidine presented a significant decrease of the latency to enter the feeding area after day $2\left(\mathrm{P} \leq 0.0001\right.$, d.f. $=4, \chi^{2}=30.744$, Friedman test; $\mathrm{P}<0.05$, Dunn test).
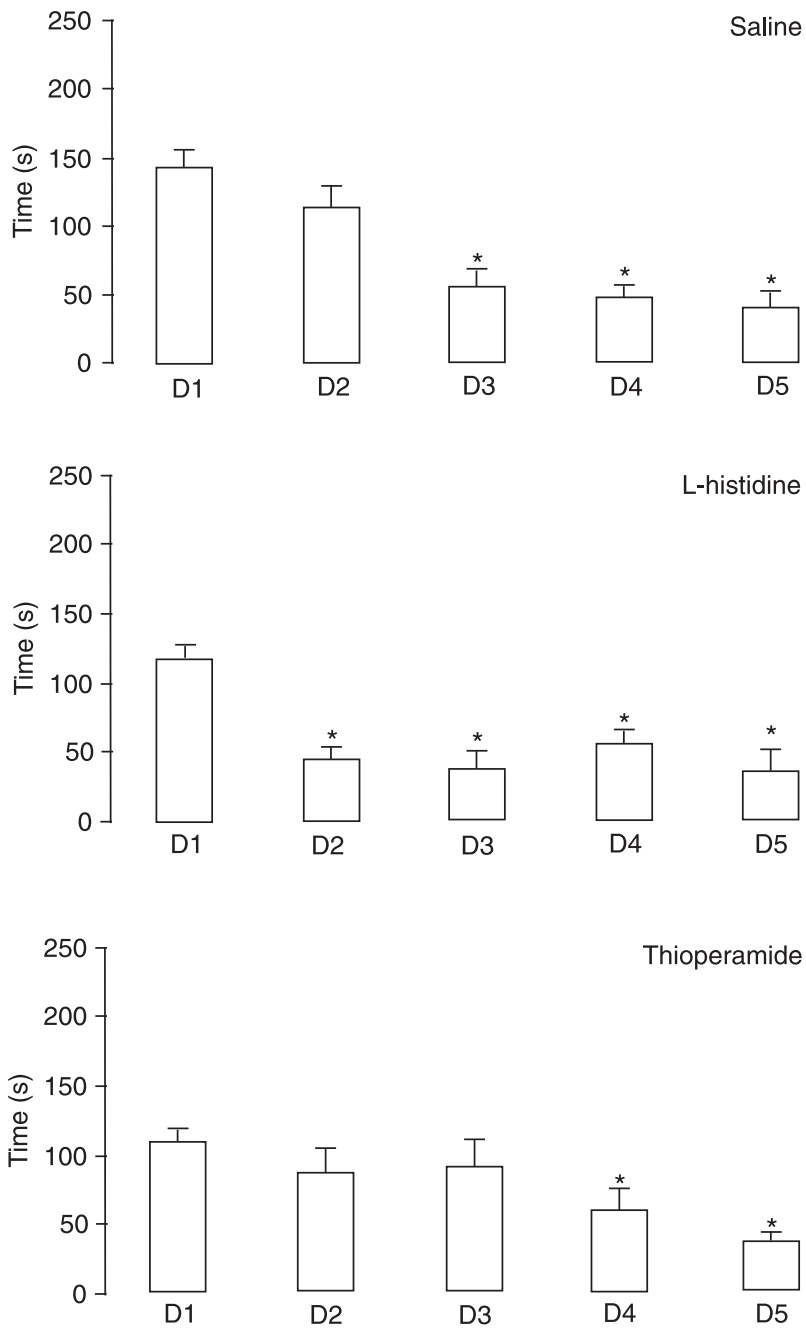

Figure 1. Latencies to enter the feeding area of non-stressed animals treated with saline $(\mathrm{N}=26), 100 \mathrm{mg} / \mathrm{kg}$ L-histidine $(\mathrm{N}=$ 25) and $10 \mathrm{mg} / \mathrm{kg}$ thioperamide $(\mathrm{N}=24)$ on the 5 training days (D1, D2, D3, D4, and D5). Data are reported as means \pm SEM. ${ }^{*} \mathrm{P}<0.05$ compared to D1 (Friedman test followed by the Dunn test when appropriate). 

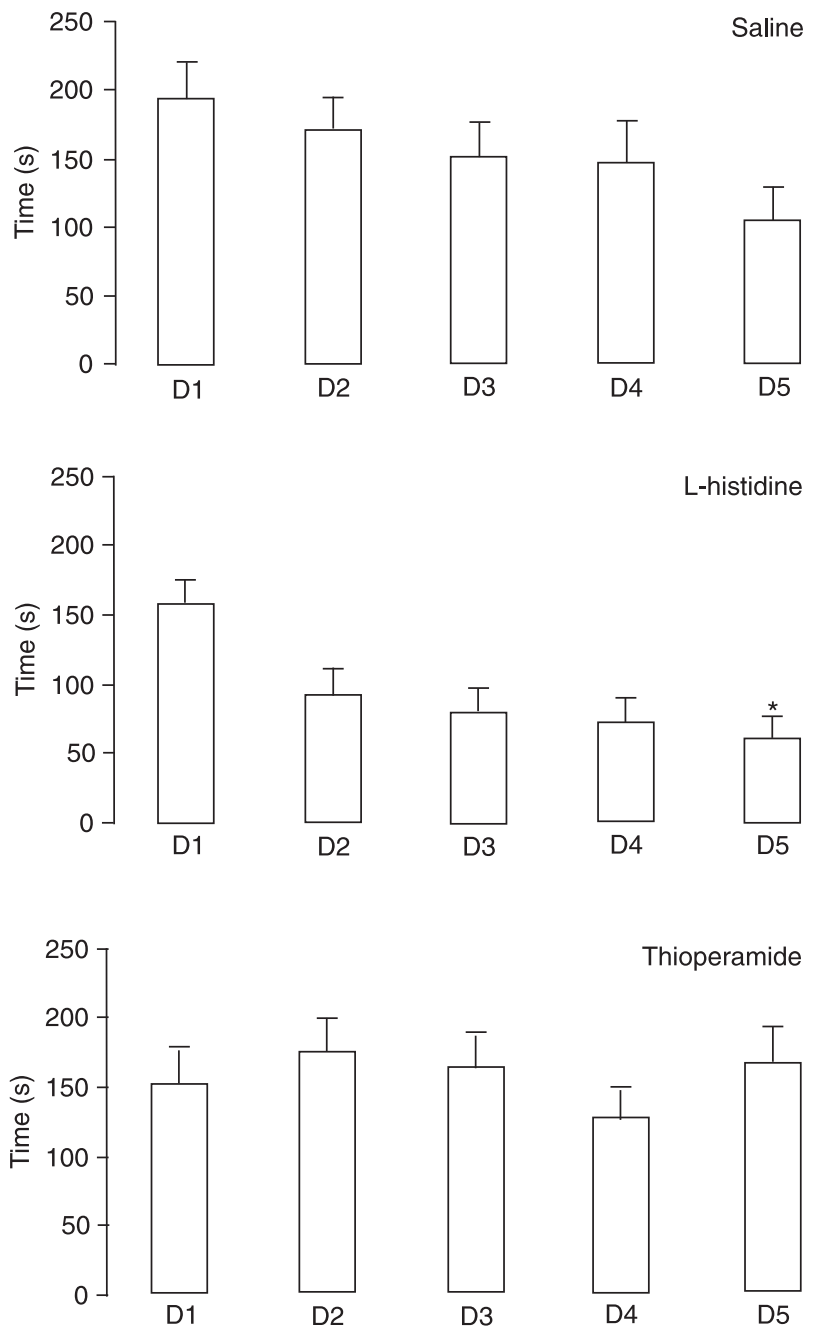

Figure 2. Latencies to enter the feeding area of animals submitted to confinement stress and treated with saline $(\mathrm{N}=18), 100$ $\mathrm{mg} / \mathrm{kg}$ L-histidine $(\mathrm{N}=18)$ and $10 \mathrm{mg} / \mathrm{kg}$ thioperamide $(\mathrm{N}=22)$ on the 5 training days (D1, D2, D3, D4, and D5). Data are reported as means \pm SEM. ${ }^{*} P<0.05$ compared to $D 1$ (Friedman test followed by the Dunn test when appropriate).

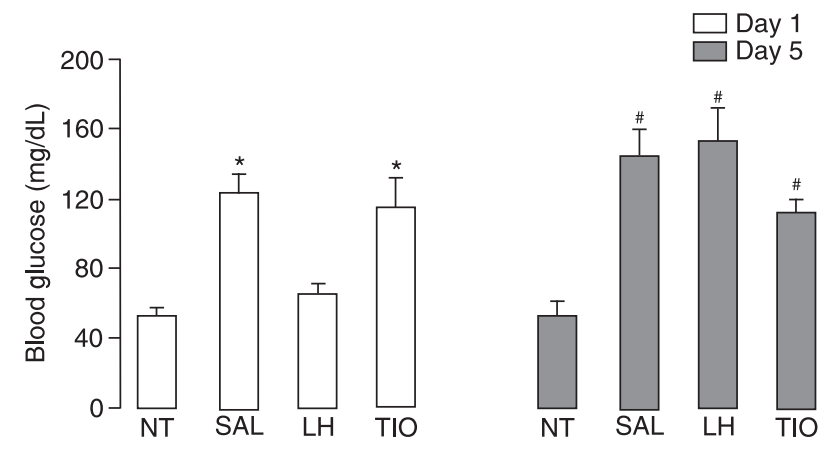

The data for stressed animals are shown in Figure 2. The animals submitted to the stress procedure and treated with saline presented a decreased latency to enter the feeding area $\left(P=0.0482\right.$, Friedman test, d.f. $=4, \chi^{2}=$ 9,5778 ); however, the Dunn multiple comparisons test did not reveal differences between training days. Animals treated with L-histidine presented a significant decrease in the latency to enter the feeding area, with a statistically significant difference between days 1 and $5(P=0.0012$, Friedman test, d.f. $=4, \chi^{2}=17.9889 ; \mathrm{P}<0.05$, Dunn test). The animals treated with thioperamide did not present a decrease in latency to enter the feeding area as observed in the animals treated with saline or $L$-histidine $(P=0.6172$, Friedman test, d.f. $\left.=4, \chi^{2}=2.6545\right)$.

Effect of stress on the latency to enter the feeding area on day 1 of training

The Mann-Whitney $U$-test indicated that the animals of experiment 1 presented a significantly lower latency to enter the feeding area on the first day of training (D1: $141.92 \pm 13.57)$ than the animals submitted to stress on the same day of training $(D 1=217.5 \pm 25.66$; $P=0.02$, Mann-Whitney U-test).

\section{Effect of stress on blood glucose}

Two-way ANOVA indicated a difference between the different groups $(P=0.0083$, d.f. $=41, F=4.52)$ and days of treatment $(P<0.001$, d.f. $=1, F=25.72$; Figure 3$)$. The Student-Newman-Keuls test indicated that the animals submitted to the stress procedure and treated with saline presented higher blood glucose levels compared to control animals that were not submitted to the stress and did not receive drug treatment. The blood glucose level of stressed animals that received thioperamide was higher than that of the control group, while stressed animals that received Lhistidine presented a level similar to that of the control group.

Figure 3. Blood glucose levels of animals pre-treated with saline (SAL, $\mathrm{N}=10$ ), $100 \mathrm{mg} / \mathrm{kg}$ L-histidine ( $\mathrm{LH}, \mathrm{N}=8$ ), or $10 \mathrm{mg} / \mathrm{kg}$ thioperamide (TIO, N = 9) and submitted to one (day 1, D1) or five sessions of confinement stress (day 5 (D5), SAL: $N=13$, $\mathrm{LH}: \mathrm{N}=10, \mathrm{TIO}: \mathrm{N}=10$ ). Animals not submitted to confinement stress (NT) that did not receive drug treatment were used as blood glucose control after $1(\mathrm{~N}=6)$ or 5 days $(\mathrm{N}=7)$ in the experimental aquarium. Data are reported as means \pm SEM. ${ }^{*} P$ $<0.05$ compared to NT-D1; \#P < 0.05 compared to NT-D5 (twoway ANOVA followed by the Student-Newman-Keuls test). 
After 5 days of stress exposure, animals treated with saline, L-histidine and thioperamide presented higher blood glucose levels compared to control.

\section{Discussion}

In the present study, animals had to associate the interruption of aeration with food offering. Animals submitted to the learning procedure that received saline presented a decrease in the latency to enter the feeding area, indicating that the animals were able to learn the task.

The animals treated with L-histidine also presented a decrease of the latency to enter the feeding area. Indeed, the drug treatment facilitated learning. Facilitatory effects of histamine and L-histidine have been observed in previous studies. Both intracerebroventricular injection of histamine and ip injection of histidine presented proactive effects against memory deficits induced by nucleus basalis lesion in rats (25). In goldfish, L-histidine had a facilitatory effect on appetitive learning (26).

In zebrafish, the injection of the histidine decarboxylase inhibitor, alpha-fluoromethylhistidine, significantly increased the time to find the goal tank in a T-maze, suggesting that the lack of histamine may impair long-term memory (2). L-histidine is a histaminergic precursor, which increases brain histamine levels. Thus, the memory facilitation observed in the L-histidine-treated group may be the result of an increase in brain histamine levels following L-histidine administration.

Animals treated with thioperamide presented a delay in learning, indicating the inhibitory effect of this drug. Since thioperamide is an $\mathrm{H}_{3}$ receptor antagonist that increases brain histamine $(27,28)$, a facilitatory effect of this drug was expected. Many studies have indicated that $\mathrm{H}_{3}$ receptor blockade by selective antagonists improves cognition in different animal models of learning involving mice and rats, such as one-trial inhibitory avoidance task (29), two-trial place recognition test (30) and spatial learning (23).

Besides being histaminergic auto-receptors, $\mathrm{H}_{3}$ receptors also function as presynaptic heteroreceptors controlling the release of serotonin (31), acetylcholine (32) and several other neurotransmitters $(33,34)$. It has been shown that histaminergic $\mathrm{H}_{3}$ antagonists (ciproxifan, clobenpropit and thioperamide), directly administered to the basolateral amygdala, decreased spontaneous acetylcholine release. Also, rats receiving intra-basolateral amygdala injections of the $\mathrm{H}_{3}$ antagonists at doses similar to those inhibiting spontaneous acetylcholine release showed memory consolidation impairment of contextual fear conditioning (35). A possible inhibition of acetylcholine release resulting from the treatment with thioperamide could be responsible for the learning deficit observed in the group that received this drug.

Since evidence suggests that there is a relationship between learning impairment and stress (36), and that brain histamine is related to both processes $(1,10)$, we investigated learning in animals submitted to confinement stress and treated with histaminergic drugs (L-histidine and thioperamide). Blood glucose analysis was carried out in order to observe the effectiveness of confinement as a stressor and also the possible effects of the drugs on stress. Some studies have indicated that blood glucose analysis carried out using blood glucose monitors may not always be reliable. For example, humidity or temperature may interfere with the monitor reading (37). However, in the present study, the blood glucose levels of non-stressed animals were similar to the plasma glucose levels of nonstressed Nile tilapia determined by a colorimetric method $(15,38)$. Despite the different types of stressors used in these studies, such as electroshock, a social stressor (38) and air emersion (15), the glucose increase following confinement stress was similar to the increase observed in the present study. Thus, although the use of a blood glucose monitor is not the standard method used in stress studies, it proved to be a reliable method to establish if stress is present.

Blood glucose analysis indicated that a single confinement session enhanced the blood glucose level of the animals, indicating stress. Previous work had already shown that confinement is an effective stressor, which causes enhanced cortisol release (39).

Despite the confinement, stressed animals treated with saline were able to learn the task. However, this procedure delayed the learning of the task, since animals submitted to the stress presented higher latencies to enter the feeding area than non-stressed animals. Other studies have shown that different kinds of stress are capable of delaying or impairing learning $(18,40)$ and it seems that cognitive impairment caused by stress is related to specific alterations in brain homeostasis, involving the neuroimmune and neuroendocrine systems as well as neurogenesis (17).

The stressed animals treated with L-histidine presented a facilitation of learning since the results for this group were similar to those observed in the non-stressed group. It seems that this amino acid attenuated the memory disruption caused by stress. This drug also attenuated the memory disruption induced by immobilization stress in rodents (40). In addition, blood analysis indicated that this drug blocked the blood glucose increase caused by confinement. Thus, the facilitatory effect observed in this group might be secondary to the effect of L-histidine on stress. 
Further studies are needed to investigate this question.

While thioperamide delayed learning in non-stressed animals, it prevented this occurrence in stressed fish. It is possible that a decrease of acetylcholine release induced by this drug added to the impairment of learning caused by the stress procedure could result in the blockage of learning observed in this group.

Taken together, the results of this experiment show that the histaminergic system enhances learning and modulates stress responses in zebrafish.

\section{Acknowledgments}

The authors would like to thank Ms. Tereza Fatori for technical assistance.

\section{References}

1. Haas H, Panula P. The role of histamine and the tuberomammillary nucleus in the nervous system. Nat Rev Neurosci 2003; 4: 121-130.

2. Peitsaro N, Kaslin J, Anichtchik OV, Panula P. Modulation of the histaminergic system and behaviour by alphafluoromethylhistidine in zebrafish. J Neurochem 2003; 86: 432-441.

3. Panula $\mathrm{P}$, Yang HY, Costa E. Histamine-containing neurons in the rat hypothalamus. Proc Natl Acad Sci U S A 1984; 81: 2572-2576.

4. Airaksinen MS, Flugge G, Fuchs E, Panula P. Histaminergic system in the tree shrew brain. J Comp Neurol 1989; 286: 289-310.

5. Airaksinen MS, Panula P. Comparative neuroanatomy of the histaminergic system in the brain of the frog Xenopus laevis. J Comp Neurol 1990; 292: 412-423.

6. Panula P, Airaksinen MS, Pirvola U, Kotilainen E. A histamine-containing neuronal system in human brain. Neuroscience 1990; 34: 127-132.

7. Kaslin J, Panula P. Comparative anatomy of the histaminergic and other aminergic systems in zebrafish (Danio rerio). $J$ Comp Neurol 2001; 440: 342-377.

8. Guo S. Linking genes to brain, behavior and neurological diseases: what can we learn from zebrafish? Genes Brain Behav 2004; 3: 63-74.

9. Frisch C, Hasenohrl RU, Haas HL, Weiler HT, Steinbusch HW, Huston JP. Facilitation of learning after lesions of the tuberomammillary nucleus region in adult and aged rats. Exp Brain Res 1998; 118: 447-456.

10. Brown RE, Stevens DR, Haas HL. The physiology of brain histamine. Prog Neurobiol 2001; 63: 637-672.

11. Tsigos C, Chrousos GP. Hypothalamic-pituitary-adrenal axis, neuroendocrine factors and stress. J Psychosom Res 2002; 53: 865-871.

12. Chrousos GP, Gold PW. The concepts of stress and stress system disorders. Overview of physical and behavioral homeostasis. JAMA 1992; 267: 1244-1252.

13. Wendelaar Bonga SE. The stress response in fish. Physiol Rev 1997; 77: 591-625.

14. Vijayan MM, Pereira C, Grau EG, Iwama GK. Metabolic responses associated with confinement stress in Tilapia: the role of cortisol. Comp Biochem Phisiol 1997; 116C: 8995.

15. Barcellos LJG, Nicolaiewsky S, De Souza SMG, Lulhier F.
Plasmatic levels of cortisol in the response to acute stress in Nile tilapia, Oreochromis niloticus (L.), previously exposed to chronic stress. Aquac Res 1990; 30: 437-444.

16. Song L, Che W, Min-Wei W, Murakami Y, Matsumoto K. Impairment of the spatial learning and memory induced by learned helplessness and chronic mild stress. Pharmacol Biochem Behav 2006; 83: 186-193.

17. Li S, Wang C, Wang W, Dong H, Hou P, Tang Y. Chronic mild stress impairs cognition in mice: from brain homeostasis to behavior. Life Sci 2008; 82: 934-942.

18. Laudien H, Freyer J, Erb R, Denzer D. Influence of isolation stress and inhibited protein biosynthesis on learning and memory in goldfish. Physiol Behav 1986; 38: 621-628.

19. Moreira PSA, Volpato GL. Conditioning of stress in Nile tilapia. J Fish Biol 2004; 64: 961-969.

20. Barreto RE, Volpato GL. Evaluating feeding as unconditioned stimulus for conditioning of an endocrine effect in Nile tilapia. Physiol Behav 2007; 92: 867-872.

21. Moreira PS, Pulman KG, Pottinger TG. Extinction of a conditioned response in rainbow trout selected for high or low responsiveness to stress. Horm Behav 2004; 46: 450-457.

22. Barreto RE, Volpato GL, Pottinger TG. The effect of elevated blood cortisol levels on the extinction of a conditioned stress response in rainbow trout. Horm Behav 2006; 50: 484-488.

23. Komater VA, Buckley MJ, Browman KE, Pan JB, Hancock AA, Decker MW, et al. Effects of histamine H3 receptor antagonists in two models of spatial learning. Behav Brain Res 2005; 159: 295-300.

24. Mattioli R, Nelson CA, Huston JP, Spieler RE. Conditioned place-preference analysis in the goldfish with the $\mathrm{H} 1$ histamine antagonist chlorpheniramine. Brain Res Bull 1998; 45: 41-44.

25. Chen Z, Shen YJ. Effects of brain histamine on memory deficit induced by nucleus basalis-lesion in rats. Acta Pharmacol Sin 2002; 23: 66-70.

26. Medalha CC, Mattioli R. Involvement of the histaminergic system on appetitive learning and its interaction with haloperidol in goldfish. Neurosci Lett 2007; 418: 195-200.

27. Arrang JM, Garbarg M, Lancelot JC, Lecomte JM, Pollard $\mathrm{H}$, Robba $\mathrm{M}$, et al. Highly potent and selective ligands for histamine H3-receptors. Nature 1987; 327: 117-123.

28. Hill SJ. Distribution, properties, and functional characteristics of three classes of histamine receptor. Pharmacol Rev 
1990; 42: 45-83.

29. Bernaerts $\mathrm{P}$, Lamberty $\mathrm{Y}$, Tirelli E. Histamine $\mathrm{H} 3$ antagonist thioperamide dose-dependently enhances memory consolidation and reverses amnesia induced by dizocilpine or scopolamine in a one-trial inhibitory avoidance task in mice. Behav Brain Res 2004; 154: 211-219.

30. Orsetti M, Ghi P, Di Carlo G. Histamine H(3)-receptor antagonism improves memory retention and reverses the cognitive deficit induced by scopolamine in a two-trial place recognition task. Behav Brain Res 2001; 124: 235-242.

31. Fink K, Schlicker E, Neise A, Gothert M. Involvement of presynaptic $\mathrm{H} 3$ receptors in the inhibitory effect of histamine on serotonin release in the rat brain cortex. Naunyn Schmiedebergs Arch Pharmacol 1990; 342: 513-519.

32. Clapham J, Kilpatrick GJ. Histamine H3 receptors modulate the release of $[3 \mathrm{H}]$-acetylcholine from slices of rat entorhinal cortex: evidence for the possible existence of $\mathrm{H} 3$ receptor subtypes. Br J Pharmacol 1992; 107: 919-923.

33. Schlicker E, Fink K, Detzner M, Gothert M. Histamine inhibits dopamine release in the mouse striatum via presynaptic H3 receptors. J Neural Transm Gen Sect 1993; 93: 1-10.

34. Schlicker E, Kathmann M, Detzner M, Exner HJ, Gothert M. $\mathrm{H} 3$ receptor-mediated inhibition of noradrenaline release: an investigation into the involvement of $\mathrm{Ca}^{2+}$ and $\mathrm{K}^{+}$ions, $\mathrm{G}$ protein and adenylate cyclase. Naunyn Schmiedebergs
Arch Pharmacol 1994; 350: 34-41.

35. Passani MB, Cangioli I, Baldi E, Bucherelli C, Mannaioni PF, Blandina P. Histamine H3 receptor-mediated impairment of contextual fear conditioning and in-vivo inhibition of cholinergic transmission in the rat basolateral amygdala. Eur J Neurosci 2001; 14: 1522-1532.

36. Elizalde N, Gil-Bea FJ, Ramirez MJ, Aisa B, Lasheras B, Del Rio J, et al. Long-lasting behavioral effects and recognition memory deficit induced by chronic mild stress in mice: effect of antidepressant treatment. Psychopharmacology 2008; 199: 1-14.

37. Haller MJ, Shuster JJ, Schatz D, Melker RJ. Adverse impact of temperature and humidity on blood glucose monitoring reliability: a pilot study. Diabetes Technol Ther 2007; 9: 1-9.

38. Barreto RE, Volpato GL. Stress responses of the fish Nile tilapia subjected to electroshock and social stressors. Braz J Med Biol Res 2006; 39: 1605-1612.

39. Volpato GL, Barreto RE. Environmental blue light prevents stress in the fish Nile tilapia. Braz J Med Biol Res 2001; 34: 1041-1045.

40. Paul VN, Chopra K, Kulkarni SK. Histaminergic modulation of stress-induced analgesia and cognitive dysfunction. Methods Find Exp Clin Pharmacol 2002; 24: 413-419. 